\title{
Relative importance of fuel management, ignition management and weather for area burned: evidence from five landscape-fire-succession models
}

\author{
Geoffrey J. Cary $\mathrm{A}, \mathrm{B}, \mathrm{H}$, Mike D. Flannigan ${ }^{\mathrm{C}}$, Robert E. Keane ${ }^{\mathrm{D}}$, \\ Ross A. Bradstock ${ }^{\mathrm{B}, \mathrm{E}}$, lan D. Davies ${ }^{\mathrm{A}}$, James M. Lenihan ${ }^{\mathrm{F}}$, \\ Chao $\mathrm{Li}^{\mathrm{G}}$, Kimberley A. Logan ${ }^{\mathrm{C}}$ and Russell A. Parsons ${ }^{\mathrm{D}}$ \\ AThe Fenner School of Environment and Society, Linnaeus Way (Building 48), College of Medicine, \\ Biology \& Environment, The Australian National University, Canberra, ACT 0200, Australia. \\ ${ }^{B}$ Bushfire Cooperative Research Centre, Level 5, 340 Albert St., East Melbourne, VIC 3002, Australia. \\ ${ }^{C}$ Canadian Forest Service, 1219 Queen St. East, Sault Ste Marie, ON, P6A 2E5, Canada. \\ DUSDA Forest Service, Rocky Mountain Research Station, Missoula Fire Sciences Laboratory, \\ 5775 W Broadway St., Missoula, MT 59808, USA. \\ EDepartment of Environment and Climate Change (NSW), PO Box 1967, Hurstville, \\ NSW 1481, Australia. \\ FUSDA Forest Service, Pacific Northwest Research Station, Corvallis Forestry Sciences Laboratory, \\ 3200 SW Jefferson Way, Corvallis, OR 97331, USA. \\ ${ }^{G}$ Canadian Forest Service, Northern Forestry Centre, 5320-122nd St., Edmonton, AB, T6H 3S5, Canada. \\ ${ }^{\mathrm{H}}$ Corresponding author. Email: geoffrey.cary@anu.edu.au
}

\begin{abstract}
The behaviour of five landscape fire models (CAFÉ, FIRESCAPE, LAMOS(HS), LANDSUM and SEMLAND) was compared in a standardised modelling experiment. The importance of fuel management approach, fuel management effort, ignition management effort and weather in determining variation in area burned and number of edge pixels burned (a measure of potential impact on assets adjacent to fire-prone landscapes) was quantified for a standardised modelling landscape. Importance was measured as the proportion of variation in area or edge pixels burned explained by each factor and all interactions among them. Weather and ignition management were consistently more important for explaining variation in area burned than fuel management approach and effort, which were found to be statistically unimportant. For the number of edge pixels burned, weather and ignition management were generally more important than fuel management approach and effort. Increased ignition management effort resulted in decreased area burned in all models and decreased number of edge pixels burned in three models. The findings demonstrate that year-to-year variation in weather and the success of ignition management consistently prevail over the effects of fuel management on area burned in a range of modelled ecosystems.
\end{abstract}

Additional keywords: CAFÉ, fire management, FIRESCAPE, LAMOS, LANDSUM, model comparison, SEM-LAND, simulation modelling.

\section{Introduction}

Debates over factors determining spatial variation in fire regimes are controversial and lack consensus (Crutzen and Goldammer 1993; Keeley et al. 1999; Dale et al. 2001; Bradstock et al. 2002). Several studies have demonstrated the overriding influence of climate and weather on area burned compared with other factors (Swetnam 1993; Bessie and Johnson 1995; Flannigan and Wotton 2001; Hély et al. 2001; Keane et al. 2003; Flannigan et al. 2005; Cary et al. 2006). The efficacy of fire prevention, including fuel management and fire suppression are also the subject of considerable debate (Minnich and Chou 1997; Finney 2001; Miyanishi and Johnson 2001).
A variety of studies have shown that fuel management reduces the incidence and area of unplanned fires in fire-prone ecosystems, although there are many unresolved questions about the generality and longevity of the effects (Fernandes and Botelho 2003). Fuel treatments can be classified according to a range of criteria including location of asset protected (in situ v. ex situ), cost, tradeoffs, and difficulty of implementation (Bradstock and Gill 2001). There are considerable unresolved questions over the importance of spatial arrangement, extent and type of fuel treatments for ameliorating area burned by unplanned fires.

Simulation modelling provides an important tool for evaluating the effect of fuel management and other fire management 
alternatives on unplanned area burned (Cary and Bradstock 2003). Conducting meaningful field experiments at the appropriate spatial and temporal scale, and with sufficient replication, is problematic and resource-intensive. Keane et al. (2004) identified 42 published landscape-fire succession models, several of which are suitable for simulating fires over large areas and long timeframes. An evaluation of effectiveness of alternative fire management approaches across a suite of these models would provide greater insights than an analysis based on any one model (Cary et al. 2006) because effects resulting from the formulation of individual models may be as important as the management effects being addressed. Individual landscape fire models are presently used to assess management effects on fire regimes (Bradstock and Gill 2001; Shang et al. 2004; Bradstock et al. 2005; Piñol et al. 2005; King et al. 2006) although insights into consistency of results among models with different formulations are elusive.

A previous study by Cary et al. (2006) explored the relative importance of key natural factors that influence area burned across five independently developed landscape fire models in a standardised design. They examined the sensitivity of simulated area burned to variation in terrain, fuel pattern, climate and weather. Sensitivity was measured as the variance in area burned explained by each of the four factors, and all of the interactions among them, in a standard generalised linear modelling analysis. Cary et al. (2006) found modelled area burned was most influenced by variation in climate and weather, with area burned sensitive to each of these factors in four models and to their interaction in three. The approach developed by Cary et al. (2006) can also be used for evaluating fuel and fire management alternatives.

The objectives of the present paper are to quantify the relative importance of fuel and ignition management and weather to variation in area and edge pixels burned in five landscape fire models. Area burned is relevant to management of forest assets, wildlife, water and other values in the interior of vegetated landscapes, whereas the extent to which edges burn is important for understanding the potential impact of fire on assets adjacent to fire-prone landscapes. Direct comparison with the importance of other determinants of variation in fire regimes, including terrain and climate, are achieved by incorporating the same weather treatments used by Cary et al. (2006). More specifically, the first question is concerned with how much variation in area burned (measured as the total number of pixels burned) and number of edge pixels burned, is explained by variation in fuel management approach and effort, ignition management effort, and weather? The second is how consistent are results across five landscape fire models that have been developed independently for different ecosystems from around the world?

\section{Models}

The models evaluated here represent considerable variation in possible formulation of fire ignition and spread modules, among others (Keane et al. 2004). They simulate patterns of fire on large landscapes, over long time periods using daily weather data. Modelled fire events are combined, over time, into patterns of fire regime. Four of the models (FIRESCAPE (Cary and Banks 1999; Cary 2002), LAMOS(HS) (Lavorel et al. 2000), LANDSUM
Table 1. Fuel condition representing low and high fuel state (load, age or successional stage) characteristics for five landscape-fire simulation models

\begin{tabular}{lll}
\hline Model & Low fuel age or load & High fuel age or load \\
\hline CAFÉ & $<0.8 \mathrm{~kg} \mathrm{~m}^{-2}$ fine litter & $>0.8 \mathrm{~kg} \mathrm{~m}^{-2}$ fine litter \\
FIRESCAPE & $0.4 \mathrm{~kg} \mathrm{~m}^{-2}$ fine litter & $1.4 \mathrm{~kg} \mathrm{~m}^{-2}$ fine litter \\
LAMOS(HS) & $0.5 \mathrm{~kg} \mathrm{~m}^{-2}$ fine litter & $1.6 \mathrm{~kg} \mathrm{~m}^{-2}$ fine litter \\
LANDSUM & Early seral succession class & Late seral succession class \\
SEM-LAND & 5 years since fire & 100 years since fire \\
\hline
\end{tabular}

(Keane et al. 2002), SEM-LAND (Li 2000)) are identical to those compared by Cary et al. (2006), with the exception of LAMOS(HS), which was modified to use an hourly time-step instead of a daily one. The fifth model, CAFÉ (Bradstock et al. 1998a, 2006), has not previously been included in experiments involving model comparison (Cary et al. 2006).

\section{Methods}

The landscape fire models were run across a four-factor experimental design incorporating variation in fuel management approach, fuel management effort, ignition management effort, and weather. Simulation landscapes were 250000 ha in size and comprised an array of 1000 by 1000 square pixels, each 0.25 ha $(50 \times 50 \mathrm{~m})$ in area. The simulation landscape was flat, with elevation assigned as the mean value of the real landscape for which each model was initially developed. Landscapes edges were treated as distinct rather than as being continuous with opposite edges.

For each model, two fuel states were defined. A 'low fuel' state represented fuel age, load or seral stage (depending on the approach to modelling fuel dynamics used in the model) typical of vegetation recently managed for fuel reduction. A 'high fuel' state was defined as that typical of vegetation with a high fuel load or age, or late seral stage, for the corresponding study region (Table 1).

\section{Fuel management approach}

Three different patterns of low fuel age or load patches were simulated across landscapes that were otherwise composed of high fuel age or load. These were: (i) a randomly distributed treatment (Random); (ii) an edge treatment (Edge); and (iii) a fuel break in the interior of the landscape (Fuel break). For the random treatment, $50 \times 50$ pixel ( $625 \mathrm{ha})$ patches of low fuel age or load were randomly allocated across the simulation landscape. Modelled area burned has been demonstrated to be relatively insensitive to scale of fuel patchiness for these types of models (Cary et al. 2006), so only one resolution of treatment was investigated here. Edge treatments involved borders of low fuel age or load immediately adjacent to the edge of the simulation landscape. Fuel break treatments involved two bands of low fuel age or load that bisected the simulation landscape in each dimension (Fig. 1).

\section{Fuel management effort}

Four levels of fuel management effort were invoked for each fuel management approach (Random, Edge, Fuel break). In defining 
(a)

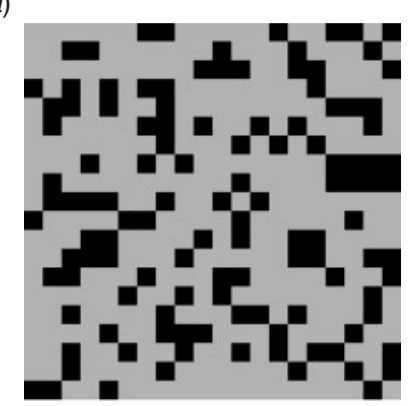

(b)

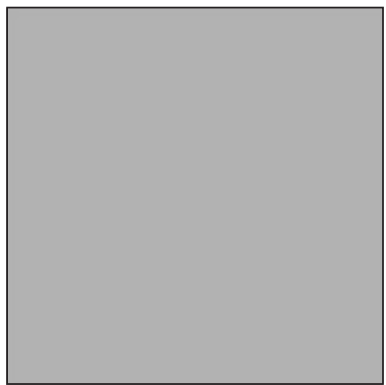

(c)

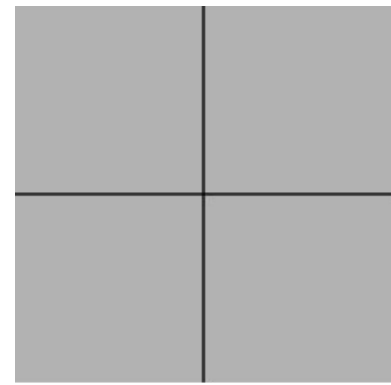

Fig. 1. Examples of different approaches to fuel management: $(a)$ random treatment (30\% low fuel age or load); $(b)$ edge treatment (150 m low fuel age or load edge); and (c) fuel breaks in the interior of the landscape ( $300 \mathrm{~m}$ low fuel age or load break). Light grey represents higher fuel load or age and black represents lower fuel age or load.

Table 2. Definition of levels of fuel management effort for different approaches to fuel management

Percentages are of landscape in low fuel state

\begin{tabular}{lcccrr}
\hline Fuel management effort & \multicolumn{4}{c}{ Fuel management approach } \\
& Random (\%) & \multicolumn{2}{c}{ Edge treatment } & \multicolumn{2}{c}{ Fuel break } \\
& & Width $(\mathrm{m})$ & $(\%)$ & Width (m) & $(\%)$ \\
\hline Zero & 0 & 0 & 0.0 & 0 & 0.0 \\
Low & 10 & 50 & 0.4 & 100 & 0.4 \\
Moderate & 20 & 100 & 0.8 & 200 & 0.8 \\
High & 30 & 150 & 1.2 & 300 & 1.2 \\
\hline
\end{tabular}

the particular levels of effort, it is assumed that more effort is required per area treated when undertaking fuel-reduction measures (prescribed burning, mechanical fuel reduction) adjacent to assets at the edge of management landscapes compared with prescribed burning in more remote locations (random approach) (Bradstock and Gill 2001), although this may be somewhat offset by the increased time and difficulty related to assembling resources in more remote locations. Similarly, it is also assumed that constructing linear fuel breaks requires more effort per area treated than random fuel treatments that are typically achieved by prescribed burning. Therefore, for the random fuel treatment, any particular level of management effort involves a greater proportion of landscapes in a low fuel state than the edge or fuel break treatments, which are approximately equivalent. Definitions for different management effort according to management approach are given in Table 2.

\section{Fuel map replication}

For the random fuel treatment, five replicate fuel maps were generated for each management effort by randomly allocating low fuel age or load to $50 \times 50$ pixel ( $625 \mathrm{ha}$ ) patches so that the different fuel ages were present in the specified ratio (Table 2). Cary et al. (2006) included 10 fuel map replicates in their landscape fire model comparison but in the current study, five replicates were used as a compromise between capturing variation arising from fuel map replication and maintaining a simulation experiment that was computationally viable. Only one arrangement of different fuel age or load is possible for each level of effort associated with the edge and fuel break treatments. 'Replication' for these management treatments was achieved using the same map, but invoking five unique random number seeds.

\section{Ignition management effort}

Ignitions in the models result from either lightning or anthropogenic sources, or both, depending on the model. In the present study, ignition management abstractly represents a variety of management actions that may include rapid initial attack of fires, education programs aimed at preventing accidental and deliberate fire lighting, and preventing access to the interiors of flammable landscapes. The four levels of ignition management effort were represented by multiplying the proportions of scheduled or modelled fire ignitions that resulted in spreading fires by 0.25 (high effort), 0.5 (moderate effort), 0.75 (low effort) and 1.0 (zero effort). For a given level of ignition management effort, for each scheduled or modelled fire ignition, a uniformly distributed random number between zero and one (inclusive) was generated and compared with the relevant probability of ignition. Random numbers lower than or equal to the probability of ignition were treated as successful, whereas those greater than the threshold were not.

\section{Weather}

Simulations were performed using weather similar to that observed at the location that each model had been previously 
Table 3. Weather datasets used for selection of replicate weather-years for simulation experiments

\begin{tabular}{lll}
\hline Location & $\begin{array}{l}\text { Data record } \\
\text { length }\end{array}$ & Model(s) \\
\hline Corsica, France & 38 years & LAMOS(HS) \\
Edson, AB, Canada & 34 years & SEM-LAND \\
Ginninderra, ACT, Australia & 42 years ${ }^{\mathrm{A}}$ & FIRESCAPE, CAFÉ \\
Glacier National Park, MT, USA & 42 years & LANDSUM \\
\hline
\end{tabular}

A Simulated data (other data sources are observed).

parameterised and tested (Table 3). For CAFÉ and FIRESCAPE, data generated from an algorithm (modified from Richardson 1981) that produces sequences of weather with the same underlying statistical properties as observed data from the Australian Capital Territory were used.

It was not possible to use the same weather data for each model for two reasons (Cary et al. 2006): (i) each model required a unique set of weather parameters, and no single weather dataset satisfied the diverse requirements of all models; and (ii) we did not want to introduce uncertainty by using input data outside each model's validation domain. However, the amount of variability between replicate weather-years was standardised across all models (Cary et al. 2006). For each location, 10 year-long sequences of daily weather data were selected from the longerterm weather sequences - typically $\sim 40$ years in duration - so that the distribution in both the annual average of daily temperature $\left({ }^{\circ} \mathrm{C}\right)$ and the annual average of daily precipitation $(\mathrm{mm})$ best matched the distribution of each of those variables from the available observed data (Cary et al. 2006).

\section{Simulation methodology and data analysis}

A total of 2400 year-long simulations were conducted for each model (three fuel management approaches by four levels of fuel management effort by five fuel map replicates (or unique random number seeds) by four levels of ignition management effort by 10 weather years). Similarly to Cary et al. (2006), fires affected fuel load or age within each simulation but, given that simulations were composed of a single year, algorithms of vegetation succession were not invoked. The total number of pixels and the number of edge pixels burned per year were recorded for each simulation.

The sensitivity of total pixels burned, and number of edge pixels burned, to variation in fuel management approach and effort, ignition management effort, and weather was measured as the variance in pixels burned explained by each of the factors and all possible interactions (Cary et al. 2006). Variance explained $\left(\mathrm{r}^{2}\right)$ was determined from two separate, fully factorial ANOVAs performed in the $S A S$ statistical package (SAS Institute Inc., Cary, NC). In each case, total pixels and number of edge pixels burned were transformed using the natural logarithm (ln) to avoid highly skewed residuals that occur with data of this type (Cary et al.2006). Factors and interactions that explained more than 5\% of the total variation in pixels burned were considered important. Trends in average pixels burned resulting from these factors were investigated to explore consistency among models.
The sensitivity of total and edge pixels burned to variation in fuel management effort, ignition management, and weather was also determined in a similar fashion for each fuel management approach separately. The objective of these analyses was to specifically examine the relative importance of fuel management effort without complex interactions arising from other approaches to fuel management.

\section{Results}

Total pixels burned

The ln-transformed total pixels burned were sensitive to variation in ignition management effort and weather, but not to fuel management approach and level of effort, in all five simulation models (Table 4). Variation in weather explained between 9 and $88 \%$ of total variation in total pixels burned, whereas ignition management effort explained between 7 and 25\%. Variation in fuel management approach and effort each explained less than $5 \%$ of variation in all models. The four-way interaction among all factors explained $\sim 5 \%$ of total variation in pixels burned for CAFÉ.

Increasing levels of ignition management effort resulted in decreasing numbers of pixels burned in all models (Table 5). Across models, the average number of pixels burned was approximately nine times greater with zero ignition management effort, compared with the high level of ignition management. By comparison, the average number of pixels burned across models was 360 times greater in the most severe weather year (most pixels burned) compared with the least severe weather year (least pixels burned), although the differences ranged between six times (CAFÉ) and over 1000 times (LANDSUM).

When variation in total pixels burned was analysed separately for each of the different fuel management approaches, sensitivity to fuel management effort was only considered important for the random fuel management approach in LAMOS(HS) (Table 6). In this case, the greatest amount of management effort $(30 \%$ of landscape in a low fuel state) reduced the average number of pixels burned by $63 \%$ compared with no management effort (Table 7). Comparative values for other models ranged from a $26 \%$ reduction (CAFÉ) to a $40 \%$ reduction (FIRESCAPE, LANDSUM and SEM-LAND) (Table 7).

\section{Edge pixels burned}

The sensitivity of ln-transformed number of edge pixels burned to variation in ignition management effort was important for CAFÉ, FIRESCAPE and LAMOS(HS). Sensitivity to weather was important for FIRESCAPE, LAMOS(HS), LANDSUM and SEM-LAND (Table 8). Ignition management explained between 7 and $12 \%$ of variation in number of edge pixels burned for these models, whereas weather explained between 15 and $79 \%$. Only in the case of CAFÉ was variation in number of edge pixels burned arising from fuel management approach (and its interaction with fuel management effort) considered important, with $37 \%$ of total variation explained by those factors.

Increasing levels of ignition management resulted in a decreasing number of edge pixels burned in three models (Table 9). For models with an important management effect (Tables 8 and 9), the average number of edge pixels burned was 
Table 4. Relative sums of squares attributed to different sources of variation in the comparison of sensitivity of In-transformed annual total pixels burned to fuel management approach (Fuel (Approach)), fuel management effort (Fuel (Effort)), ignition management effort (Ignition) and weather (Weather) factors, and their interactions

Factors and their interactions are considered important if they explain more than 0.05 of total variance respectively. Factors and interactions considered unimportant are blank. Significant factors and interactions $(P<0.05)$ are indicated by an asterisk $(*)$. Note that not all significant sources are considered important

\begin{tabular}{|c|c|c|c|c|c|c|}
\hline \multirow[t]{2}{*}{ Source of variation } & \multirow[t]{2}{*}{ d.f. } & \multicolumn{5}{|c|}{ Model } \\
\hline & & CAFÉ & FIRESCAPE & LAMOS(HS) & LANDSUM & SEM-LAND \\
\hline Fuel (Approach) & 2 & & $*$ & $*$ & & $*$ \\
\hline Fuel (Effort) & 3 & & $*$ & $*$ & & $*$ \\
\hline Fuel (Approach) $\times$ Fuel (Effort) & 6 & & $*$ & $*$ & & $*$ \\
\hline Ignition & 3 & $0.25 *$ & $0.19 *$ & $0.25 *$ & $0.08 *$ & $0.07 *$ \\
\hline Fuel $($ Approach $) \times$ Ignition & 6 & & & & & \\
\hline Fuel $($ Effort $) \times$ Ignition & 9 & & & & & \\
\hline Fuel $($ Approach $) \times$ Fuel $($ Effort $) \times$ Ignition & 18 & & & & & \\
\hline Weather & 9 & $0.09 *$ & $0.40^{*}$ & $0.16^{*}$ & $0.69 *$ & $0.88^{*}$ \\
\hline Fuel (Approach) $\times$ Weather & 18 & & & & & $*$ \\
\hline Fuel $($ Effort $) \times$ Weather & 27 & & & & & $*$ \\
\hline Fuel $($ Approach $) \times$ Fuel $($ Effort $) \times$ Weather & 54 & & & & & * \\
\hline Ignition $\times$ Weather & 27 & & & & $*$ & * \\
\hline Fuel $($ Approach $) \times$ Ignition $\times$ Weather & 54 & & & & & $*$ \\
\hline Fuel $($ Effort $) \times$ Ignition $\times$ Weather & 81 & & & & & \\
\hline Fuel $($ Approach $) \times$ Fuel $($ Effort $) \times$ Ignition $\times$ Weather & 162 & $0.05^{*}$ & & & & \\
\hline Model & 479 & 0.46 & 0.68 & 0.43 & 0.83 & 0.98 \\
\hline
\end{tabular}

Table 5. Average ( $\pm 95 \%$ confidence interval, CI) In-transformed annual total pixels burned for different levels of ignition management effort for CAFÉ, FIRESCAPE, LAMOS(HS), LANDSUM and SEM-LAND

\begin{tabular}{|c|c|c|c|c|c|}
\hline \multirow[t]{2}{*}{ Ignition management effort } & \multicolumn{5}{|c|}{ Average ln pixels burned $( \pm 95 \% \mathrm{CI})$} \\
\hline & CAFÉ & FIRESCAPE & LAMOS(HS) & LANDSUM & SEM-LAND \\
\hline Zero & $11.4(0.09)$ & $9.5(0.09)$ & $10.8(0.08)$ & $6.0(0.29)$ & $7.0(0.08)$ \\
\hline Low & $11.0(0.10)$ & $9.2(0.10)$ & $10.5(0.09)$ & $5.4(0.30)$ & $6.7(0.08)$ \\
\hline Moderate & $10.4(0.11)$ & $8.8(0.11)$ & $10.0(0.11)$ & $4.6(0.29)$ & $6.2(0.08)$ \\
\hline High & $9.4(0.12)$ & $7.6(0.12)$ & $8.8(0.15)$ & $3.1(0.28)$ & $5.6(0.08)$ \\
\hline
\end{tabular}

Table 6. Relative sums of squares of In-transformed annual total pixels burned attributed to variation in fuel management effort for each fuel management approach when analysed separately

Fuel management effort is considered important if it explains more than 0.05 of total variance. Factors considered unimportant are blank. Significant factors and interactions $(P<0.05)$ are indicated by an asterisk $(*)$. Note that not all significant sources are considered important

\begin{tabular}{|c|c|c|c|c|c|c|}
\hline \multirow[t]{2}{*}{ Fuel management approach } & \multirow[t]{2}{*}{ d.f. } & \multicolumn{5}{|c|}{ Model } \\
\hline & & CAFÉ & FIRESCAPE & LAMOS(HS) & LANDSUM & SEM-LAND \\
\hline Random treatment & 3 & & $*$ & $0.62 *$ & & $*$ \\
\hline Edge treatment & 3 & & & & & \\
\hline Interior fuel break & 3 & & & & & \\
\hline
\end{tabular}

six times greater with zero ignition management effort, compared with the high level of ignition management. By comparison, the average number of edge pixels burned was 320 greater in the most severe weather year (most pixels burned) compared with the least severe weather year (least pixels burned), although the difference again varied considerably among models, ranging between eight times (CAFÉ) and 1500 times (SEM-LAND).

Fuel management approach and effort were both considered important for edge pixels burned in CAFÉ, while an important interaction between fuel management approach and weather was 
Table 7. Average ( $\pm 95 \%$ confidence interval, $\mathrm{CI})$ In-transformed total pixels burned per annum for varying fuel management effort (proportion of landscape in lower fuel state) for random fuel treatment for CAFÉ, FIRESCAPE, LAMOS(HS), LANDSUM and SEM-LAND

\begin{tabular}{lccccc}
\hline Proportion & & \multicolumn{3}{c}{ Average ln pixels burned $( \pm 95 \%$ CI $)$} & \\
& CAFÉ & FIRESCAPE & LAMOS(HS) & LANDSUM & SEM-LAND \\
\hline 0 & $10.7(0.23)$ & $9.0(0.20)$ & $10.2(0.20)$ & $5.0(0.52)$ & $6.5(0.28)$ \\
10 & $10.6(0.22)$ & $8.7(0.20)$ & $10.0(0.21)$ & $4.9(0.53)$ & $6.3(0.26)$ \\
20 & $10.5(0.21)$ & $8.6(0.19)$ & $9.6(0.21)$ & $4.7(0.52)$ & $6.1(0.24)$ \\
30 & $10.4(0.22)$ & $8.5(0.19)$ & $9.2(0.23)$ & $4.5(0.52)$ & $6.0(0.23)$ \\
\hline
\end{tabular}

Table 8. Relative sums of squares attributed to different sources of variation in the comparison of sensitivity of In-transformed annual number of edge pixels burned to fuel management approach (Fuel (Approach)), fuel management effort (Fuel (Effort)), ignition management effort (Ignition) and weather (Weather) factors, and their interactions

Factors and their interactions are considered important if they explain more than 0.05 of total variance respectively. Factors and interactions considered unimportant are blank. Significant factors and interactions $(P<0.05)$ are indicated by an asterisk $(*)$. Note that not all significant sources are considered important

\begin{tabular}{|c|c|c|c|c|c|c|}
\hline \multirow[t]{2}{*}{ Source of variation } & \multirow[t]{2}{*}{ d.f. } & \multicolumn{5}{|c|}{ Model } \\
\hline & & CAFÉ & FIRESCAPE & LAMOS(HS) & LANDSUM & SEM-LAND \\
\hline Fuel (Approach) & 2 & $0.27 *$ & * & $*$ & $*$ & $*$ \\
\hline Fuel (Effort) & 3 & $*$ & $*$ & $*$ & $*$ & $*$ \\
\hline Fuel (Approach) $\times$ Fuel (Effort) & 6 & $0.10^{*}$ & $*$ & & $*$ & $*$ \\
\hline Ignition & 3 & $0.09 *$ & $0.07 *$ & $0.12 *$ & & $*$ \\
\hline Fuel $($ Approach $) \times$ Ignition & 6 & $*$ & & & & $*$ \\
\hline Fuel (Effort) $\times$ Ignition & 9 & & $*$ & & & \\
\hline Fuel $($ Approach $) \times$ Fuel (Effort) $\times$ Ignition & 18 & $*$ & & & & \\
\hline Weather & 9 & $*$ & $0.16^{*}$ & $0.15^{*}$ & $0.37 *$ & $0.79 *$ \\
\hline Fuel $($ Approach $) \times$ Weather & 18 & & & & $0.09 *$ & $*$ \\
\hline Fuel (Effort) $\times$ Weather & 27 & & & & $*$ & * \\
\hline Fuel $($ Approach $) \times$ Fuel $($ Effort $) \times$ Weather & 54 & & * & & $*$ & $*$ \\
\hline Ignition $\times$ Weather & 27 & & & & $*$ & $*$ \\
\hline Fuel $($ Approach $) \times$ Ignition $\times$ Weather & 54 & & & & & * \\
\hline Fuel $($ Effort $) \times$ Ignition $\times$ Weather & 81 & & & & & \\
\hline Fuel $($ Approach $) \times$ Fuel $($ Effort $) \times$ Ignition $\times$ Weather & 162 & & $0.05^{*}$ & & & \\
\hline Model & 479 & 0.66 & 0.47 & 0.39 & 0.65 & 0.91 \\
\hline
\end{tabular}

Table 9. Average ( $\pm 95 \%$ confidence interval, CI) In-transformed annual edge pixels burned for different levels of ignition management effort for CAFÉ, FIRESCAPE and LAMOS(HS)

\begin{tabular}{lccc}
\hline \multirow{2}{*}{$\begin{array}{l}\text { Ignition management } \\
\text { effort }\end{array}$} & \multicolumn{3}{c}{ Average ln edge pixels burned $( \pm 95 \% \mathrm{CI})$} \\
& CAFÉ & FIRESCAPE & LAMOS(HS) \\
\hline Zero & $3.9(0.21)$ & $2.3(0.16)$ & $3.3(0.15)$ \\
Low & $3.4(0.19)$ & $1.9(0.16)$ & $3.0(0.16)$ \\
Moderate & $2.9(0.19)$ & $1.6(0.15)$ & $2.3(0.16)$ \\
High & $1.9(0.17)$ & $0.9(0.12)$ & $1.4(0.15)$ \\
\hline
\end{tabular}

identified for LANDSUM (Table 8). The separate analyses of sensitivity of edge pixels burned to fuel management effort, for each fuel management approach, demonstrates that the level of effort was important for the edge treatment approach for CAFÉ, FIRESCAPE and LANDSUM (Table 10). For these models, the average number of edge pixels burned was reduced, on average, by $\sim 89 \%$ when maximum effort was invoked, compared with no management effort (Table 11).

\section{Discussion}

Variation in weather has previously been shown as important in determining modelled area burned in a similar landscape fire model comparison (Cary et al. 2006) and in fire-prone ecosystems (Bessie and Johnson 1995; Hély et al. 2001; Flannigan et al. 2005). The results presented here demonstrate that variation in both weather and ignition management consistently prevail over fuel management effects, consistently for area burned, and in a majority of models for number of edge pixels burned.

Fuel amount and fuel treatments are important in determining area burned by unplanned fires (Fernandes and Botelho 2003; King et al. 2006), and a decline in total area burned with increased randomly located fuel management effort was found for all models. However, the effect was only considered 
Table 10. Relative sums of squares of In-transformed annual edge pixels burned attributed to variation in fuel management effort for each fuel management approach when analysed separately

Fuel management effort is considered important if it explains more than 0.05 of total variance. Factors considered unimportant are blank. Significant factors and interactions $(P<0.05)$ are indicated by an asterisk $(*)$. Note that not all significant sources are considered important

\begin{tabular}{|c|c|c|c|c|c|c|}
\hline \multirow[t]{2}{*}{ Fuel management approach } & \multirow[t]{2}{*}{ d.f. } & \multicolumn{5}{|c|}{ Model } \\
\hline & & CAFÉ & FIRESCAPE & LAMOS(HS) & LANDSUM & SEM-LAND \\
\hline Random treatment & 3 & & $*$ & $*$ & $*$ & $*$ \\
\hline Edge treatment & 3 & $0.60 *$ & $0.19^{*}$ & $*$ & $0.14 *$ & $*$ \\
\hline Interior fuel break & 3 & & & & & \\
\hline
\end{tabular}

Table 11. Average ( $\pm 95 \%$ confidence interval, $C I)$ In-transformed edge pixels burned per annum for varying widths of edge treatments for CAFÉ, FIRESCAPE and LANDSUM

\begin{tabular}{lccc}
\hline Width (pixels) & \multicolumn{3}{c}{ Average ln edge pixels burned $( \pm 95 \%$ CI $)$} \\
& CAFÉ & FIRESCAPE & LANDSUM \\
\hline 0 & $4.02(0.30)$ & $2.00(0.27)$ & $0.98(0.29)$ \\
1 & $0.25(0.15)$ & $2.09(0.28)$ & $0.02(0.03)$ \\
2 & $0.32(0.15)$ & $0.61(0.17)$ & $0.01(0.01)$ \\
3 & $0.14(0.08)$ & $0.38(0.13)$ & $0.00(0.00)$ \\
\hline
\end{tabular}

important in the case of LAMOS(HS), and only when data from different fuel management approaches were analysed separately (Table 6). For the remaining models, the maximum effort in fuel treatment (30\% of landscape in low fuel state) resulted in an approximately commensurate reduction in area burned, a relatively small effect compared with variation arising from weather and ignition management. Nevertheless, fuel treatment may reduce fire intensity (Byram 1959) and fire severity (Hammill and Bradstock 2006), although these were not measured in our experiment because not all models were capable of simulating them. Reduced fire intensity can enhance fire suppression capacity (Fernandes and Botelho 2003) and there is considerable interest in incorporating intensity and severity effects into further research of the type presented here. All levels of fuel management effort in our study may be below the critical threshold required to limit fire spread (Gardner et al. 1987) and the comparative effectiveness of fuel management effort may have been higher in landscapes that were otherwise more heterogeneous (Fernandes and Botelho 2003).

Increased effort towards fuel treatment at the edge of landscapes was not expected to be important in determining area burned because of the disconnect between the treatment and the interior, where most fires occurred. It might be expected, however, that increased effort towards treating edges would have resulted in an important declining effect on the number of edge pixels burned, because the treatment and edge pixels are colocated. This combination resulted in the only instance where fuel management was considered important in its own right (Table 8), although analysis of the edge treatment separately indicated that increased effort towards this approach had important effects in several models (Tables 10 and 11). Interior fuel breaks were consistently unimportant for both area burned and number of edge pixels burned, presumably because the arrangement used here did not divide the interior of the landscape sufficiently to prevent large areas being burned, and because it was too remote from the edge to have an important effect there.

The amount of variation in both area burned and number of edge pixels burned explained by weather differed among models. This may result from variation in model formulation or differences in severity of the weather years for each model (Cary et al. 2006). For example, in LANDSUM, considerably more area burned in one year compared with all others, mimicking the effect of long-term drought in real Rocky Mountain landscapes (Keane et al. 2006). Similar dynamics characterise boreal ecosystems (SEM-LAND) (Li et al. 2000). Variation in area burned explained by weather was lower for the other models, as might be expected for systems with less year-to-year variation in fire weather severity (Cary et al. 2006).

Our simulation results showed area burned tended to decrease with increasing levels of ignition management effort for all models. Debates about the effects of fire suppression on area burned are contentious (Miyanishi and Johnson 2001; Ward et al. 2001; Cumming 2005) although a direct comparison with our results is constrained by our stated definition of ignition management that incorporates a wider range of phenomena than fire suppression alone. The efficacy and success or otherwise of these management actions often depends on interacting variables including weather conditions, fuel moisture and load, and vegetation type, as is the case with likelihood of initial attack success (Pyne et al. 1996; Cary 2005). These interactions were not included in the model comparison experiment because they were beyond the scope of the study objectives. Therefore, the results concerning ignition management effort should be interpreted with appropriate care.

Ignition management explained less variation in the number of edge pixels burned than it did for area burned, presumably because a large number of fires never reached the edge of the simulation landscape, particularly in the case of CAFÉ and LANDSUM. An improved simulation experiment, involving smaller landscapes or greater numbers of ignitions overall, would result in a decrease in the number of zero values in the results for these models.

Differences in model behaviour are also likely to result from differences in model formulation (Keane et al. 2004). For example, Cary et al. (2006) found that models representing ignition in a more complex, mechanistic fashion can exhibit enhanced 
sensitivity of area burned to variation in environmental factors over simpler models. Generalised insights into the relationship between model formulation and behaviour are generally lacking but would provide significant benefits in explaining variation in the results of the present study to any particular approach to modelling fire at the landscape scale.

Similarly, different models require varying numbers of replicate runs to guarantee reproducible results. The number of replicate runs within each level of the four main factors in our design was very large, varying from 240 for weather to 800 for fuel management approach. Therefore, the average modelled area burned has been determined for each model with considerable confidence. Further, four of the models (FIRESCAPE, LAMOS, LANDSUM and SEM-LAND) were part of an earlier model comparison by Cary et al. (2006), who produced comparable results regarding the importance of weather. That is, the rank order of variation in area burned explained by weather, the common factor between the earlier analysis and that reported here, was the same for the models in common. This indicates a high level of repeatability in the model results based on the number of replications included in our design.

Different approaches to fuel management also differ with respect to the effort required to meet similar management objectives. In the present study, each particular level of fuel management effort was treated as equivalent across the different approaches to fuel management (Table 2). Although this allowed a balanced design for the analysis of results, and has similarities with the approach of Bradstock and Gill (2001), in reality, management effort depends on a large number of interacting variables associated with ecosystem type, circumstances concerning the assets being protected, including position in the landscape and predominant wind direction (Finney 2001, 2007), and resources available for management. The abstract and simple landscapes used in the present study do not facilitate consideration of such cases but served well in providing an unbiased platform for comparison between models. These caveats should be considered in any attempt to extrapolate our results to any particular management situation. Nevertheless, separate analysis for each fuel management approach, where assumptions about equivalence of effort do not need to be invoked, indicate that targeted management effort was relatively unimportant for area burned (Table 6) but more important for number of edge pixels burned (Table 10). In the models where variation in effort towards edge treatment was found important in relation to the number of edge pixels burned, the reduction in edge pixels burned was very much greater than the number of pixels treated.

Our findings can be generalised to areas of forest or shrubland vegetation adjacent to assets of high economic value including residential areas and plantations of fire-killed species. Management of the wildland-urban interface (WUI) (Radeloff et al. 2005 ) is one of the most pressing issues in fire management (Moritz and Stephens 2008) because of the value of assets involved and extraordinary length of the WUI around cities in locations such as south-eastern Australia (Bradstock et al. 1998b), southern California and elsewhere in the United States (Hammer et al. 2007). There remains, in these and similar areas, considerable debate about the effectiveness of broad-area prescribed burning, relative importance of weather compared with fuel and ignition management overall (Fernandes and Botelho
2003), and the possible impacts of future climates on facets of this problem (Fried et al. 2008).

Models that have been developed independently can be used to produce independent evidence for or against the generality of any finding (Cary et al. 2006). However, concerns are periodically raised over the robustness of findings from individual models (Krebs 2003). The extent to which the selection and parameterisation of a particular model has influenced results is often raised. Multiple-model comparisons provide for greater consensus in the robustness of the findings when results from all, or a majority of, the models are somewhat consistent (Bugmann et al. 1996). Future results from experiments using individual models that behave generally consistently in comparison studies might also prove reasonably robust, although the extent to which the experiment deviated from that conducted here would be critical. Therefore, there is considerable value in the findings regarding model consistency in the present study to a broad range of existing landscape fire modelling research involving the models that were included here.

Similarly to Cary et al. (2006), several factors and their interactions resulted in significant effects $(P<0.05)$, but they were unimportant for explaining variance in the areas burned. We have adopted the view of Cary et al. (2006) that "variance explained is a more meaningful measure when comparing the importance of environmental variables in determining landscape dynamics such as area burned, particularly when dealing with simulated data'. It facilitates the comparison of models with a focus on the extent to which they exhibit consistent trends in behaviour rather than on the absolute differences that would inevitably arise from differences in model formulation and weather data.

Our comparison involved standardising model input and output to facilitate meaningful comparison between models. The extent to which results might be affected by the translation of standardised input data in different models needs to be explored. However, a generally high level of consistency in the results from different models, particularly for area burned, indicates that the experiment appears reasonably robust from this perspective. There is, therefore, potential for extending the general approach developed by Cary et al. (2006) and in the current study to compare other aspects of landscape fire model behaviour. Vegetation succession is important to the dynamics of fire-prone landscapes and it has not been included in the comparison of landscape fire models to date. There is considerable potential for repeating the Cary et al. (2006) experiment, and the one detailed here, to explore the importance of vegetation succession in understanding the relative importance of natural and management factors that determine spatial variation in fire regimes.

\section{Conclusions}

Weather and ignition management effort were more important than fuel management approach and effort in determining total area burned in five landscape fire models. Modelled area burned decreased with increasing levels of ignition management effort in all models. Increasing effort in a random fuel reduction approach resulted in decreased areas burned in the model systems but the effects were unimportant compared with that of varying weather and level of ignition management. Similarly, variation in the number of edge pixels burned depended largely 
on weather and ignition management effort, although fuel management approach was found to be important in one model. Consistency among modelled trends was high for simulated area burned, providing evidence for consensus among modelled results. Trends were somewhat less consistent for number of edge pixels burned, although there was sufficient similarity among models for the findings to be considered robust.

\section{Acknowledgements}

Sandra Lavorel contributed suggestions regarding the experimental design. Hong He contributed suggestions about approaches for analysing the results and interpreting the findings. Scott Stephens and Malcolm Gill are gratefully acknowledged for comments on an earlier manuscript. The Program for Energy Research and Development (PERD) of Natural Resources Canada and the US National Fire Plan are gratefully acknowledged for partially funding the present research.

\section{References}

Bessie WC, Johnson EA (1995) The relative importance of fuels and weather on fire behaviour in subalpine forests. Ecology 76, 747-762 doi: $10.2307 / 1939341$

Bradstock RA, Gill AM (2001) Living with fire and biodiversity at the urban edge: in search of a sustainable solution to the human protection problem in southern Australia. Journal of Mediterranean Ecology 2, 179-195.

Bradstock RA, Bedward M, Kenny BJ, Scott J (1998a) Spatially explicit simulation of the effect of prescribed burning on fire regimes and plant extinctions in shrublands typical of south-eastern Australia. Biological Conservation 86, 83-95. doi:10.1016/S0006-3207(97)00170-5

Bradstock RA, Gill AM, Kenny BJ, Scott J (1998b) Bushfire risk at the urban interface estimated from historical weather records: consequences for the use of prescribed fire in the Sydney region of southeastern Australia. Journal of Environmental Management 52, 259-271. doi:10.1006/JEMA.1997.0177

Bradstock RA, Williams JE, Gill AM (Eds) (2002) 'Flammable Australia: the Fire Regimes and Biodiversity of a Continent.' (Cambridge University Press: Cambridge, UK)

Bradstock RA, Bedward M, Gill AM, Cohn JS (2005) Which mosaic? A landscape ecological approach for evaluating interactions between fire regimes, habitat and animals. Wildlife Research 32, 409-423. doi:10.1071/WR02114

Bradstock RA, Bedward M, Cohn JS (2006) The modelled effects of differing fire management strategies on the conifer Callitris verrucosa, within semi-arid mallee vegetation in Australia. Journal of Applied Ecology $\mathbf{4 3}$ 281-292. doi:10.1111/J.1365-2664.2006.01142.X

Bugmann HKM, Yan XD, Sykes MT, Martin P, Lindner M, Desanker PV, Cumming SG (1996) A comparison of forest gap models: model structure and behaviour. Climatic Change 34, 289-313. doi:10.1007/BF00224640

Byram GM (1959) Combustion of forest fuels. In 'Forest Fire: Control and Use'. (Ed. KP Davis) pp. 61-80. (McGraw-Hill: New York)

Cary GJ (2002) Importance of a changing climate for fire regimes in Australia. In 'Flammable Australia: the Fire Regimes and Biodiversity of a Continent'. (Eds R Bradstock, AM Gill, J Williams) pp. 26-46. (Cambridge University Press: Cambridge, UK)

Cary GJ (2005) Research priorities arising from the 2002-2003 bushfire season in south-eastern Australia. Australian Forestry 68, 104-111.

Cary GJ, Banks JCG (1999) Fire regime sensitivity to global climate change: an Australian perspective. In 'Biomass Burning and its Inter-Relationship with the Climate System'. (Eds J Innes, M Verstraete, M Beniston) pp. 233-246. (Kluwer Academic Publishers: Dordrecht, the Netherlands)

Cary GJ, Bradstock RA (2003) Sensitivity of fire regimes to management. In 'Australia Burning: Fire Ecology, Policy and Management Issues'. (Eds G Cary, D Lindenmayer, S Dovers) pp. 65-81. (CSIRO Publishing: Melbourne)
Cary GJ, Keane RK, Gardner RH, Lavorel S, Flannigan M, Davies ID, Li C, Lenihan JM, Rupp TS, Mouillot F (2006) Comparison of the sensitivity of landscape-fire succession models to variation in terrain, fuel pattern, climate and weather. Landscape Ecology 21, 121-137. doi:10.1007/S10980-005-7302-9

Crutzen PJ, Goldammer JG (1993) 'Fire in the Environment: the Ecological, Atmospheric and Climatic Importance of Vegetation Fires.' (Wiley: New York)

Cumming SG (2005) Effective fire suppression in boreal forests. Canadian Journal of Forest Research 35, 772-786. doi:10.1139/X04-174

Dale VH, Joyce LA, McNulty S, Neilson RP, Ayres MP, Flannigan MD, Hanson PJ, Irland LC, Lugo AE, Peterson CJ, Simberloff D, Swanson FJ, Stocks BJ, Wotton BM (2001) Forest disturbances and climate change. Bioscience 51, 723-734. doi:10.1641/0006-3568(2001) 051[0723:CCAFD]2.0.CO;2

Fernandes PM, Botelho HS (2003) A review of prescribed burning effectiveness. International Journal of Wildland Fire 12, 117-128. doi:10.1071/WF02042

Finney MA (2001) Design of regular landscape fuel treatment patterns for modifying fire growth and behavior. Forest Science 47, 219-228.

Finney MA (2007) A computational method for optimising fuel treatment locations. International Journal of Wildland Fire 16, 702-711. doi:10.1071/WF06063

Flannigan MD, Wotton BM (2001) Climate, weather and area burned In 'Forest Fires: Behaviour and Ecological Effects'. (Eds E Johnson, K Miyanishi) pp. 335-357. (Kluwer Academic Press: San Diego, CA)

Flannigan MD, Logan KA, Amiro BD, Skinner WR, Stocks BJ (2005) Future area burned in Canada. Climatic Change 72, 1-16. doi:10.1007/S10584 005-5935-Y

Fried JS, Gilless JK, Riley WJ, Moody TJ, Simon de Blas C, Hayhoe K, Moritz M, Stephens S, Tom M (2008) Predicting the effect of climate change on wildfire behavior and initial attack success. Climatic Change 87(Suppl. 1), 251-264. doi:10.1007/S10584-007-9360-2

Gardner RH, Milne BT, Turner MG (1987) Neutral models for the analysis of broad-scale landscape pattern. Landscape Ecology 1, 19-28. doi:10.1007/BF02275262

Hammer RB, Radeloff VC, Fried JS, Stewart SI (2007) Wildland-urban interface housing growth during the 1990s in California, Oregon and Washington. International Journal of Wildland Fire 16, 255-265. doi:10.1071/WF05077

Hammill KA, Bradstock RA (2006) Remote sensing of fire severity in the Blue Mountains: influence of vegetation type and inferring fire intensity. International Journal of Wildland Fire 15, 213-226. doi:10.1071/ WF05051

Hély C, Flannigan M, Bergeron Y, McRae D (2001) Role of vegetation and weather on fire behaviour in the Canadian mixedwood boreal forest using two fire behaviour prediction systems. Canadian Journal of Forest Research 31, 430-441. doi:10.1139/CJFR-31-3-430

Keane RE, Parsons R, Hessburg P (2002) Estimating historical range and variation of landscape patch dynamics: limitations of the simulation approach. Ecological Modelling 151, 29-49. doi:10.1016/S03043800(01)00470-7

Keane RE, Cary GJ, Parsons R (2003) Using simulation to map fire regimes: an evaluation of approaches, strategies, and limitations. International Journal of Wildland Fire 12, 309-322. doi:10.1071/ WF03017

Keane RE, Cary GJ, Davies ID, Flannigan MD, Gardner RH, Lavorel S, Lennihan JM, Li C, Rupp TS (2004) A classification of landscape fire succession models: spatial simulations of fire and vegetation dynamics. Ecological Modelling 179, 3-27. doi:10.1016/J.ECOLMODEL. 2004.03.015

Keane RE, Holsinger L, Pratt S (2006) Simulating historical landscape dynamics using the landscape fire succession model LANDSUM version 4.0. USDA Forest Service, Rocky Mountain Research Station, General Technical Report RMRS-GTR-171CD. (Fort Collins, CO) 
Keeley JE, Fotheringham CJ, Morais M (1999) Reexamining fire suppression impacts on brushland fire regimes. Science 284, 1829-1832. doi:10.1126/SCIENCE.284.5421.1829

King KJ, Cary GJ, Bradstock RA, Chapman J, Pyrke A, Marsden-Smedley JB (2006) Simulation of prescribed burning strategies in south-west Tasmania, Australia: effects on unplanned fires, fire regimes, and ecological management values. International Journal of Wildland Fire 15, 527-540. doi:10.1071/WF05076

Krebs C (2003) Observations on fire ecology. In 'Australia Burning: Fire Ecology, Policy and Management Issues'. (Eds G Cary, D Lindenmayer, S Dovers) pp. 229-235. (CSIRO Publishing: Melbourne)

Lavorel S, Davies ID, Noble IR (2000) LAMOS: a LAndscape MOdelling Shell. In 'Landscape Fire Modelling - Challenges and Opportunities'. (Eds B Hawkes, M Flannigan) Canadian Forest Service, Northern Forestry Centre, Information Report NOR-X-371, pp. 25-28. (Edmonton, $\mathrm{AB}$ )

Li C (2000) Reconstruction of natural fire regimes through ecological modelling. Ecological Modelling 134, 129-144. doi:10.1016/S03043800(00)00290-8

Li C, Flanningan MD, Corns IGW (2000) Influence of potential climate change on forest landscape dynamics of west central Alberta. Canadian Journal of Forest Research 30, 1905-1912. doi:10.1139/CJFR-30-121905

Minnich RA, Chou YH (1997) Wildland fire patch dynamics in the chaparral of southern California and northern Baja California. International Journal of Wildland Fire 7, 221-248. doi:10.1071/WF9970221

Miyanishi K, Johnson EA (2001) Comment - A reexamination of the effects of fire suppression in the boreal forest. Canadian Journal of Forest Research 31, 1462-1466. doi:10.1139/CJFR-31-8-1462
Moritz MA, Stephens SL (2008) Fire and sustainability: considerations for California's altered future climate. Climatic Change 87(Suppl. 1), 265-271. doi:10.1007/S10584-007-9361-1

Piñol J, Beven K, Viegas DX (2005) Modelling the effects of fire-exclusion and prescribed fire on wildfire size in Mediterranean ecosystems. Ecological Modelling 183, 397-409. doi:10.1016/J.ECOLMODEL.2004. 09.001

Pyne SJ, Andrews PL, Laven RD (1996) 'Introduction to Wildland Fire.' 2nd edn. (Wiley: New York)

Radeloff VC, Hammer RB, Stewart SI, Fried JS, Holcomb SS, McKeefry JF (2005) The wildland-urban interface in the United States. Ecological Applications 15, 799-805. doi:10.1890/04-1413

Richardson CW (1981) Stochastic simulation of daily precipitation, temperature, and solar radiation. Water Resources Research 17, 182-190. doi:10.1029/WR017I001P00182

Shang BZ, He HS, Crow TR, Shifley SR (2004) Fuel load reductions and fire risk in central hardwood forests of the United States: a spatial simulation study. Ecological Modelling 180, 89-102. doi:10.1016/ J.ECOLMODEL.2004.01.020

Swetnam TW (1993) Fire history and climate change in giant sequoia groves. Science 262, 885-889. doi:10.1126/SCIENCE.262.5135.885

Ward PC, Tithecott AG, Wotton BM (2001) Reply - A reexamination of the effects of fire suppression in the boreal forest. Canadian Journal of Forest Research 31, 1467-1480. doi:10.1139/CJFR-31-8-1467

Manuscript received 27 June 2007, accepted 17 June 2008 